\title{
Using MODIS land surface temperatures and the Crocus snow model to understand the warm bias of ERA-Interim reanalyses at the surface in Antarctica
}

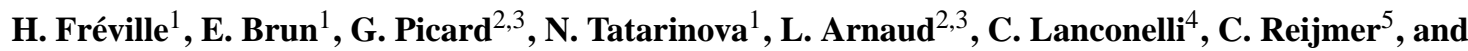 \\ M. van den Broeke \\ ${ }^{1}$ CNRM-GAME UMR3589, Météo-France and CNRS, Toulouse, France \\ ${ }^{2}$ University Grenoble Alpes, LGGE UMR5183, 38041 Grenoble, France \\ ${ }^{3}$ CNRS, LGGE UMR5183, 38041 Grenoble, France \\ ${ }^{4}$ Institute of Atmospheric Sciences and Climate, Bologna, Italy \\ ${ }^{5}$ Institute for Marine and Atmospheric Research Utrecht, University of Utrecht, Utrecht, the Netherlands \\ Correspondence to: H. Fréville (helene.freville@meteo.fr)
}

Received: 19 November 2013 - Published in The Cryosphere Discuss.: 6 January 2014

Revised: 13 May 2014 - Accepted: 15 June 2014 - Published: 31 July 2014

\begin{abstract}
Moderate-Resolution Imaging spectroradiometer (MODIS) land surface temperatures in Antarctica were processed in order to produce a gridded data set at $25 \mathrm{~km}$ resolution, spanning the period 2000-2011 at an hourly time step. The Aqua and Terra orbits and MODIS swath width, combined with frequent clear-sky conditions, lead to very high availability of quality-controlled observations: on average, hourly data are available $14 \mathrm{~h}$ per day at the grid points around the South Pole and more than $9 \mathrm{~h}$ over a large area of the Antarctic Plateau. Processed MODIS land surface temperatures, referred to hereinafter as MODIS $T_{\mathrm{S}}$ values, were compared with in situ hourly measurements of surface temperature collected over the entirety of the year 2009 by seven stations from the Baseline Surface Radiation Network (BSRN) and automatic weather stations (AWSs). In spite of an occasional failure in the detection of clouds, MODIS $T_{\mathrm{s}}$ values exhibit a good performance, with a bias ranging from -1.8 to $0.1^{\circ} \mathrm{C}$ and errors ranging from 2.2 to $4.8^{\circ} \mathrm{C}$ root mean square at the five stations located on the plateau. These results show that MODIS $T_{\mathrm{s}}$ values can be used as a precise and accurate reference to test other surface temperature data sets. Here, we evaluate the performance of surface temperature in the European Centre for MediumRange Weather Forecasts (ECMWF) reanalysis known as ERA-Interim reanalysis. During conditions detected as cloud free by MODIS, ERA-Interim shows a widespread warm bias in Antarctica in every season, ranging from +3 to $+6^{\circ} \mathrm{C}$
\end{abstract}

on the plateau. This confirms a recent study which showed that the largest discrepancies in $2 \mathrm{~m}$ air temperature between ERA-Interim and the global temperature data set HadCRUT4 compiled by the Met Office Hadley Centre and the University of East Anglia's Climatic Research Unit occur in Antarctica. A comparison with in situ surface temperature shows that this bias is not strictly limited to clear-sky conditions. A detailed comparison with stand-alone simulations by the Crocus snowpack model, forced by ERA-Interim, and with the ERA-Interim/land simulations, shows that the warm bias may be due primarily to an overestimation of the surface turbulent fluxes in very stable conditions. Numerical experiments with Crocus show that a small change in the parameterization of the effects of stability on the surface exchange coefficients can significantly impact the snow surface temperature. The ERA-Interim warm bias appears to be likely due to an overestimation of the surface exchange coefficients under very stable conditions.

\section{Introduction}

Ice-sheet melt is the largest potential source of uncertainties for future sea level rise, which has led to a growing interest in the observation and modeling of the interactions between the ice sheets and their environment. While it is clear 
that the Greenland Ice Sheet loses mass from both enhanced discharge and decreasing surface mass balance due to increased surface melting (Rignot et al., 2011), the changes in Antarctica in the recent decades have a complex signature. In this context, it is of vital importance to monitor and understand the processes controlling the surface heat and mass exchanges between the Antarctic Ice Sheet and the atmosphere. As in other regions of the world, meteorological reanalyses are commonly used, either as climate series to interpret or even detect recent changes (Bromwich et al., 2012) or as boundary conditions for regional meteorological and climate models (Van de Berg et al., 2008; Gallée and Gorodetskaya, 2010; Bromwich et al., 2013). However, the scarcity of assimilated observations constraining the analysis, along with weaknesses in the modeling of some key processes for the polar regions - such as the formation of mixed-phase clouds and the extreme stability of the atmospheric boundary layer $(\mathrm{ABL})$ - increase the uncertainty in the quality of the reanalyses over Antarctica. Nowadays, in situ observations that were not used in the re-analyses are difficult to come by, limiting our ability to evaluate the reanalyzed variables.

Following pioneering work from Comiso (2000) on the use of satellite surface temperatures to detect changes in the Antarctic climate (Schneider et al., 2004; Steig et al., 2009) and more recent work from Hall et al. $(2012,2013)$ on the detection of Greenland Ice Sheet surface melting and changes, the present study focuses on the use of remotely sensed surface temperature to evaluate the quality of reanalyses and snow model outputs under clear-sky conditions. As shown in Brun et al. (2011), surface temperature is more appropriate than $2 \mathrm{~m}$ air temperature, hereafter $T_{2} \mathrm{~m}$, for investigating the energy budget of snow-covered surfaces and evaluating some aspects of meteorological and snow models. This is particularly true in polar regions where large temperature gradients near the surface are common. In contrast to $T_{2 \mathrm{~m}}$, snow surface temperature can be estimated from spaceborne sensor observations under clear-sky conditions using the thermal emission of the surface in the infrared. In the first part of this paper, the Moderate-Resolution Imaging Spectroradiometer (MODIS) clear-sky land surface temperature (LST) values are evaluated against hourly series of in situ observations of snow surface temperature. Such an evaluation provides better insight than previous evaluations based on a comparison with near-surface temperature, as in Wang et al. (2013). In the second section, MODIS LST values from 2000 to 2011 are compared with 3 h ERA-Interim (Dee et al., 2011) snow surface temperatures and hourly snow surface temperatures simulated by the detailed snowpack model Crocus (Brun et al., 1992; Vionnet et al., 2012). A warm bias is found and its spatial and temporal variations are analyzed. Then, the causes of this bias are explored with a special focus on the turbulent flux of sensible heat under very stable conditions.

\section{Data and methods}

\subsection{MODIS land surface temperature}

Clear-sky LST values are derived from observations of the MODIS instruments on board Terra and Aqua spacecrafts. The two MODIS instruments view the entire surface of the Earth every 1-2 days at least thanks to a large swath (i.e., the cross track size of the image) of $2330 \mathrm{~km}$. We used Terra MOD11 and Aqua MYD11 products in version-5. These products were evaluated by Wan (2014) with the radiancebased method: using atmospheric temperature and water profiles and surface emissivity, the radiance-based method calculates MODIS LST values from brightness temperatures in band 31 through radiative transfer simulations. By applying this method on 42 sites, Wan (2014) found MODIS $T_{\mathrm{s}}$ errors within $\pm 2{ }^{\circ} \mathrm{C}$ for all the sites but six bare soil sites (not including South Pole). For the South Pole site, MODIS LST error is only $-0.5^{\circ} \mathrm{C}$. The accuracy of MODIS LST values depends primarily on the quality of the detection of clouds (Hall et al., 2008). When clear-sky conditions are detected, the generalized split-window land surface temperature algorithm of Wan and Dozier (1996) is used to retrieve LST values for each MODIS pixel along with emissivities in bands 31 (10.78 to 11.28 mum) and 32 (11.77 to $12.27 \mu \mathrm{m})$ (http:// modis.gsfc.nasa.gov/about/specifications.php). For the comparison with reanalysis and model outputs, the $1 \mathrm{~km}$ resolution product was projected onto a $25 \mathrm{~km}$ grid in stereographic polar projection. Once the interpolation on the stereopolar grid and the time binning are made, the MODIS LST product is referred to as MODIS $T_{\mathrm{s}}$, as MODIS snow surface temperature. To create an hourly data record of clear-sky $T_{\mathrm{S}}$ values, all data of a sufficient quality acquired within a given hour in a grid cell were averaged. The MODIS LST algorithm provides two indicators of quality: quality assurance (QA) and quality control (QC). To minimize cloud detection errors, we selected only the pixels produced with "good quality" or "fairly calibrated" according to the MODIS quality nomenclature. The data set extends from March 2000 to December 2011, as Aqua data are available only from July 2002 onward. Figure 1 shows the mean rate of available data in Antarctica over the period, for the annual mean (Fig. 1a), for winter (JJA) (Fig. 1b) and for summer (DJF) (Fig. 1c). The data availability depends on

- the revisit time of MODIS, which presents two areas of maximum controlled by the swath width $(2230 \mathrm{~km})$ and the orbit inclination. The maximum is in the area south of $87^{\circ} \mathrm{S}$ centered around the South Pole; a second local maximum is in the area extending from 71 to $87^{\circ} \mathrm{S}$;

- cloudiness, which is less marked over the Antarctic Plateau than over West Antarctica or coastal regions.

Both variables explain that the availability of hourly clearsky MODIS $T_{\mathrm{s}}$ is at its maximum around the South Pole, 

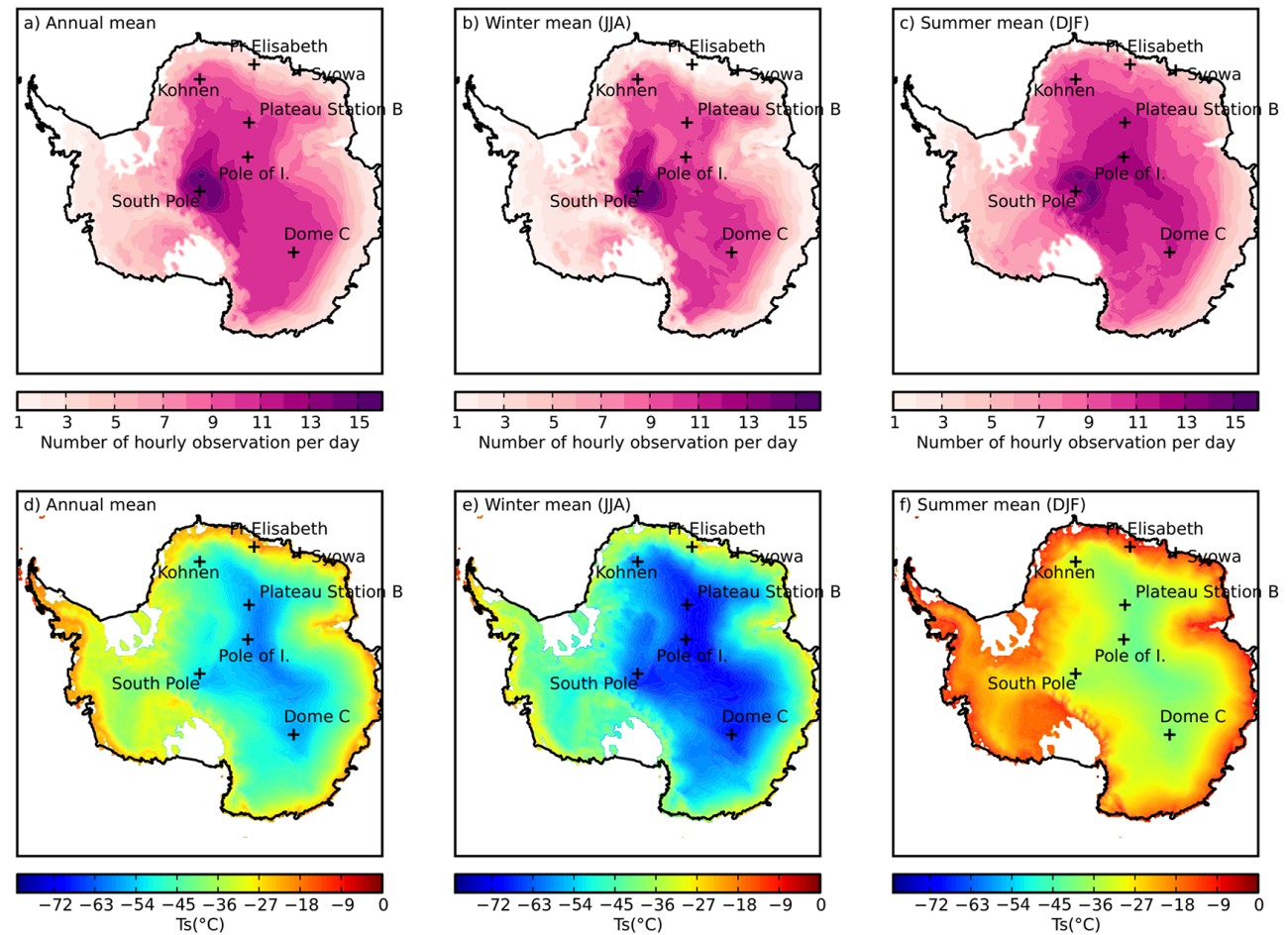

Figure 1. Averaged number of hours per day with high-quality data (2000-2011): (a) annual mean, (b) winter mean (JJA) and (c) summer mean (DJF). Averaged MODIS $T_{\mathrm{S}}$ values (2000-2011): (d) annual mean, (e) winter mean (JJA) and (f) summer mean (DJF). "Pole of I." shows the location of Pole of Inaccessibility Station.

with approximately 14 hourly $T_{\mathrm{S}}$ values available per day on average and more than 9 over a large area of the Antarctic Plateau. In the coastal areas and West Antarctica, hourly data are available for fewer than $5 \mathrm{~h}$ per day on average. MODIS LST (land surface temperature) products are not produced in ice shelf areas because of MODIS land definition. On the plateau, data availability is higher in summer than in winter. This can be explained by more frequent clouds in winter (Bromwich et al., 2012) and by more frequent failures in cloud detection during the polar night (Comiso, 2000). Figure 1d, e and $f$ show the 2000-2011 annual, winter and summer mean value of the hourly clear-sky MODIS $T_{\mathrm{S}}$ values, respectively.

\subsection{In situ observations}

Several sites in Antarctica provide near-continuous, longterm data sets of variables relevant to monitoring boundarylayer conditions. To assess the accuracy of MODIS $T_{\mathrm{S}}$ values, we processed upwelling and downwelling long-wave radiation observations $\left(\mathrm{LW}_{\mathrm{up}}\right.$ and $\left.\mathrm{LW}_{\text {down }}\right)$ provided at an hourly time step by three BSRN (Baseline Surface Radiation Network) stations (Ohmura et al., 1998): Dome C $\left(75^{\circ} 06^{\prime} \mathrm{S} 123^{\circ} 20^{\prime} \mathrm{E} ; 3233 \mathrm{~m}\right.$ a.s.l.), South Pole $\left(90^{\circ} \mathrm{S} 0^{\circ} \mathrm{E}\right.$; $2835 \mathrm{~m}$ a.s.1.), Syowa $\left(69^{\circ} \mathrm{S} 39^{\circ} 35^{\prime} \mathrm{E}\right.$; $18 \mathrm{~m}$ a.s.l.) and four automatic weather stations (AWSs) operated by the Institute for Marine and Atmospheric research, Utrecht Uni- versity (van den Broeke et al., 2004): Kohnen (AWS9) $\left(75^{\circ} \mathrm{S} 0^{\circ} 40^{\prime} \mathrm{E}\right.$; $2892 \mathrm{~m}$ a.s.1.), Plateau Station B (AWS12) $\left(78^{\circ} 38^{\prime} \mathrm{S} 35^{\circ} 38^{\prime} \mathrm{E}\right.$; $3619 \mathrm{~m}$ a.s.l.), Pole of Inaccessibility (AWS13) $\left(82^{\circ} 3^{\prime} \mathrm{S} 54^{\circ} 34^{\prime} \mathrm{E} ; 3718 \mathrm{~m}\right.$ a.s.1.), and Princess Elisabeth (AWS16), the latter operated in collaboration with the Catholic University Leuven, (Gorodetskaya et al., 2013) $\left(71^{\circ} 57^{\prime} \mathrm{S} 23^{\circ} 21^{\prime} \mathrm{E}\right.$; $1372 \mathrm{~m}$ a.s.l.). Note that the BSRN Georg Von Neumayer station $\left(70^{\circ} 39^{\prime} \mathrm{S} 8^{\circ} 15^{\prime} \mathrm{W}\right.$; $42 \mathrm{~m}$ a.s.l.) cannot be used due to its location on the Ekström ice shelf where MODIS LST products are not produced.

BSRN data were collected at stations with permanent staff, thereby ensuring regular cleaning of the pyrgeometers and limiting the perturbations due to riming, which is very frequent on the Antarctic Plateau. In contrast to BSRN, AWS pyrgeometers are visited once a year at most. van den Broeke et al. (2004) performed an evaluation of the quality of longwave radiation measured at these AWSs, which revealed frequent errors due to riming of the pyrgeometers, especially in winter. To detect erroneous measurements, the authors proposed to reject any data with $\mathrm{LW}_{\text {down }}$ larger than $\mathrm{LW}_{\text {up }}$. We further analyzed these observations and decided to use a more conservative filter: AWS data are rejected when $\mathrm{LW}_{\text {down }}$ is larger than $\mathrm{LW}_{\text {up }}-5 \mathrm{~W} \mathrm{~m}^{-2}$. This selection reduces the amount of data available for the winter. Nevertheless, we believe that some of the filtered data are still affected by riming. In order to assess the possible impact of such 
processing, we also analyzed observations from two additional pyrgeometers at Dome $\mathrm{C}$ which do not benefit from the standard BSRN cleaning procedure. They were available only for the year 2012 .

Snow surface temperature $T_{\mathrm{S}}$ at the stations was derived according to the following:

$T_{\mathrm{s}}=\sqrt[4]{\frac{\mathrm{LW}_{\mathrm{up}}-(1-\epsilon) \mathrm{LW}_{\mathrm{down}}}{\epsilon \sigma}}$,

where $\epsilon$ is snow surface emissivity, $\sigma$ is the StefanBoltzmann constant, and $T_{\mathrm{s}}$ is snow surface temperature.

In the long-wave domain $(5-40 \mu \mathrm{m})$, snow behaves almost as a blackbody. Snow emissivity has been found to range from 0.98 and 0.99 for grain size larger than $75 \mu \mathrm{m}$ and close to 0.985 for fine-grain snow with grain size equal to $50 \mu \mathrm{m}$ (Dozier and Warren, 1982). In order to derive $T_{\mathrm{s}}, \epsilon$ has been set to the constant value 0.99 as in Brun et al. (2011). Sensitivity tests with $\epsilon$ values set to 0.98 and 1.0 were made, leading to differences in surface temperature smaller than $0.1^{\circ} \mathrm{C}$ on average $\left(0.080\right.$ and $0.079^{\circ} \mathrm{C}$ respectively).

\subsection{ERA-Interim surface temperature}

The ERA-Interim reanalysis includes a comprehensive set of variables describing the surface and the ABL. We focused on the ERA-Interim skin temperature, hereafter ERA-i $T_{\mathrm{s}}$, which forms the interface between the soil and the atmosphere in the Integrated Forecast System (IFS) (European Centre for Medium-Range Weather Forecasts (ECMWF), http://www.ecmwf.int). IFS is the meteorological model and assimilation scheme used in the ERA-Interim analysis to assimilate observations. ERA-i $T_{\mathrm{S}}$ is the temperature used in the derivation of the heat budget between the atmosphere and the surface. ERA-i $T_{\mathrm{S}}$ was extracted at $0.5^{\circ}$ resolution in latitude and longitude and then projected at $25 \mathrm{~km}$ resolution on the same grid as the MODIS $T_{\mathrm{S}}$ using bilinear interpolation. This step of projection aims to facilitate the comparison between ERA-Interim data set and MODIS data set. ERA-i $T_{\mathrm{S}}$ is not produced by the ERA-Interim analysis scheme and hence does not benefit from the assimilation of any surface temperature observations. It is the result of the resolution of the energy balance equation during the forecast step of IFS. We extracted ERA-i $T_{\mathrm{S}}$ at a $3 \mathrm{~h}$ time step, at analysis time and at the 3 to $9 \mathrm{~h}$ forecast from the 0 and $12 \mathrm{~h}$ analyses. We also extracted the skin temperature from a new ECMWF product named ERA-Interim/Land (Balsamo et al., 2012). This temperature, hereinafter referred to as ERA-i/land $T_{\mathrm{s}}$, was derived from a stand-alone land-surface model simulation using the land surface model HTESSEL (Hydrology Tiled ECMWF Scheme for Surface Exchanges over Land) (Balsamo et al., 2009), with meteorological forcing from ERAInterim. ERA-i/land $T_{\mathrm{S}}$ was regridded exactly as ERA-i $T_{\mathrm{s}}$. It is available every $6 \mathrm{~h}$.

\subsection{Surface temperature simulation using Crocus snowpack model}

Within the modeling platform SURFEX (EXTernalized land and ocean SURFace platform) (Masson et al., 2013), the Crocus snowpack model (Brun et al., 1992; Vionnet et al., 2012) was run in a stand-alone mode, using meteorological forcing data from ERA-Interim. The ERA-Interim total precipitation was turned into snowfall at temperatures below $1^{\circ} \mathrm{C}$ and into rainfall above. Crocus simulates the time evolution of snow properties in homogeneous layers. The number of layers evolves adaptively and is limited to 50 in this study. Heat exchanges, solar energy absorption, snow metamorphism and compaction, phase changes, and water percolation are simulated within the snowpack along with the energy and mass exchanges in the atmosphere. The albedo is a prognostic variable, depending on the type, size and age of the crystals of the snow surface layers. To run the model, near-surface meteorological data including $T_{2 \mathrm{~m}}, 2 \mathrm{~m}$ air humidity, $10 \mathrm{~m}$ wind velocity, precipitation rate, $\mathrm{LW}_{\text {down }}, \mathrm{SW}_{\text {down }}$ and air pressure were extracted at $0.5^{\circ}$ resolution from ERA-Interim and then projected onto the $25 \mathrm{~km}$ grid (21 499 points on the ice sheet) as for ERA-i $T_{\mathrm{s}}$. Crocus results are not independent of ERAi $T_{\mathrm{S}}$ since the latter strongly influences ERA-i $T_{2 \mathrm{~m}}$ which is used as a forcing data. All the grid points were initialized with the same snow profile ( $20 \mathrm{~m}$ snow water equivalent), deduced from observations made at Dome $\mathrm{C}$ in 2009, as in Brun et al. (2011). Since this is a rough approximation, a spin-up of the model was obtained by running Crocus three times over 1 decade (forcing conditions were taken from July 1999 to July 2009) in a loop mode in order to produce an initial profile in equilibrium over each grid point with the local climate conditions. A last run was then performed from July 1999 to December 2012, in order to produce the hourly time series of snow surface temperatures used in the following, hereinafter named Crocus $T_{\mathrm{s}}$, covering the whole Antarctic continent at $25 \mathrm{~km}$ resolution.

\section{Evaluation results}

\subsection{LST MODIS evaluation}

Hourly cloud-free MODIS $T_{\mathrm{S}}$ at $25 \mathrm{~km}$ resolution, described in Sect. 2.1, was evaluated with respect to in situ observations (Sect. 2.2). The year 2009 was chosen to obtain the maximum number of available stations. Figure 2 shows the comparison between in situ $T_{\mathrm{s}}$ and MODIS $T_{\mathrm{s}}$ over the whole data set.

\subsubsection{Evaluation with respect to stations located over the plateau}

At all stations located on the plateau, MODIS $T_{\mathrm{s}}$ values exhibit biases ranging from -1.8 to $0.1^{\circ} \mathrm{C}$ and root mean square error (RMSE) values ranging from 2.2 to $4.8^{\circ} \mathrm{C}$. This 

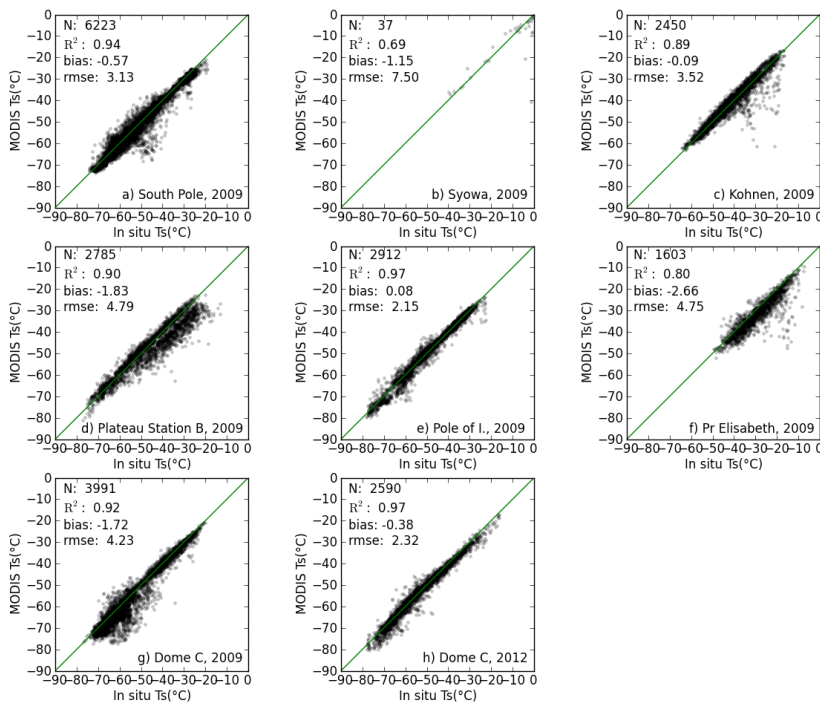

Figure 2. Comparisons of MODIS $T_{\mathrm{S}}$ and in situ $T_{\mathrm{S}}$ at (a) South Pole, (b) Syowa, (c) Kohnen base (AWS9), (d) Plateau Station B (AWS12), (e) Pole of Inaccessibility (AWS13), (f) Princess Elisabeth station (AWS16), (g) Dome C in 2009 and (h) Dome C in 2012. "Pole of I." means Pole of Inaccessibility and "Pr Elisabeth" means Princess Elisabeth. The number $N$ of simultaneous MODIS $T_{\mathrm{S}}$ and in situ $T_{\mathrm{S}}$ used in the evaluation primarily depends upon satellite overpasses and cloudiness. In AWS stations, $N$ also depends upon the filter used to select data not affected by riming. The green line represents the $1: 1$ line.

is a good performance considering the fact that the comparison is performed at an hourly time step. A significant part of the RMSE comes from a few largely underestimated MODIS $T_{\mathrm{s}}$. The examination of $\mathrm{LW}_{\text {down }}$ provided by the BSRN stations (South Pole and Dome C in 2009) reveals that the largest errors are due to erroneous detection of clearsky conditions. This is consistent with the likely underestimation of cloudiness on the plateau reported by Bromwich et al. (2012). The regression slope is very close to 1 , showing almost no seasonal variability in the MODIS $T_{\mathrm{S}}$ bias. The conservative filter described in Sect. 2.2 in AWS stations suppresses cases with a false detection of clear-sky conditions by MODIS as well. This is illustrated with Dome C 2012 better scores (Fig. 2h) compared to Dome C 2009 (Fig. 2g). In spite of the possible accumulation of several error sources - MODIS cloud detection, time shift of the MODIS data to the closest full hour time step, difference in the representative scale of the different data sets $(25 \mathrm{~km}$ for the projected MODIS $T_{\mathrm{s}}$ against a few meters for the in situ observations), occasional errors in in situ observations due to riming MODIS $T_{\mathrm{s}}$ exhibits quite good performances on the Antarctic Plateau. This confirms and extends, in space and time, the results reported in Brun et al. (2011). In this previous study, MODIS $T_{\mathrm{s}}$ over Dome C was successfully compared over a 11-day period with several independent hourly time series of snow surface temperature. The MODIS $T_{\mathrm{s}}$ data set clearly has great potential for the evaluation of surface temperature produced by model or analysis outputs in Antarctica.

\subsubsection{Evaluation with respect to coastal stations}

MODIS $T_{\mathrm{s}}$ exhibits larger errors at coastal stations. Syowa has only 37 data points, due to the quasi-permanent detection of clouds by MODIS, which limits the significance of the results. The bias is low and the $7.5^{\circ} \mathrm{C}$ RMSE is mainly due to two erroneous measurements. Princess Elisabeth Station provides a much larger data set. The cold bias $\left(-2.7^{\circ} \mathrm{C}\right)$ and the RMSE $\left(4.8^{\circ} \mathrm{C}\right)$ mainly stem from erroneous cloud detection leading in this specific case to a severe underestimation of the surface temperature. The physiographic heterogeneity around the station may also be a contributing factor. In the rest of the paper, we focus on the Antarctic Plateau, where hourly MODIS $T_{\mathrm{S}}$ values are more frequent and of better quality than in coastal regions.

\subsection{ERA-Interim and Crocus surface temperature analysis}

ERA-i $T_{\mathrm{S}}$ (3-hourly data described in Sect. 2.3) and Crocus $T_{\mathrm{S}}$ (hourly data described in Sect. 2.4) were evaluated with respect to the MODIS $T_{\mathrm{S}}$ data set over the period 2000-2011. It must be kept in mind that the latter includes only observations under meteorological conditions analyzed as cloud free by the MODIS cloud detection algorithm, hereinafter referred to simply as clear-sky conditions. Figure 3 shows the bias and Fig. 4 the RMSE of ERA-i $T_{\mathrm{S}}$ and Crocus $T_{\mathrm{S}}$ with respect to hourly MODIS $T_{\mathrm{s}}$. Era-i $T_{\mathrm{S}}$ exhibits a widespread warm bias ranging from +4 to $+6^{\circ} \mathrm{C}$ on most of the plateau. This bias is at its minimum in winter and maximum in summer around the central part of the plateau.

The Crocus $T_{\mathrm{s}}$ bias is much better, with values ranging from -2 to $+2{ }^{\circ} \mathrm{C}$ on most of the plateau. Local maxima correspond to areas where ERA-i $T_{\mathrm{S}}$ exhibits the warmest biases, which is consistent with the fact that Crocus was forced with ERA-Interim $T_{2}$ m. The difference between ERA-i $T_{\mathrm{s}}$ and Crocus $T_{\mathrm{S}}$ RMSE is largely due to the difference in their respective biases

\section{Discussion}

\subsection{Confirmation of the widespread ERA-i $T_{\mathrm{S}}$ warm bias with local in situ observations}

Genthon et al. (2010) already noted a significant warm bias in the temperature forecasted by the operational version of IFS in summer at all levels of the instrumented Dome $\mathrm{C}$ tower (sensors are located from 4.3 to $45 \mathrm{~m}$ above the surface). This warm bias was attributed to the combination of an underestimated albedo - a previous albedo evaluation from Dome $\mathrm{C}$ BSRN data provides an average value around 0.83 - and an attenuation of the nocturnal radiative cooling. ERA-Interim 

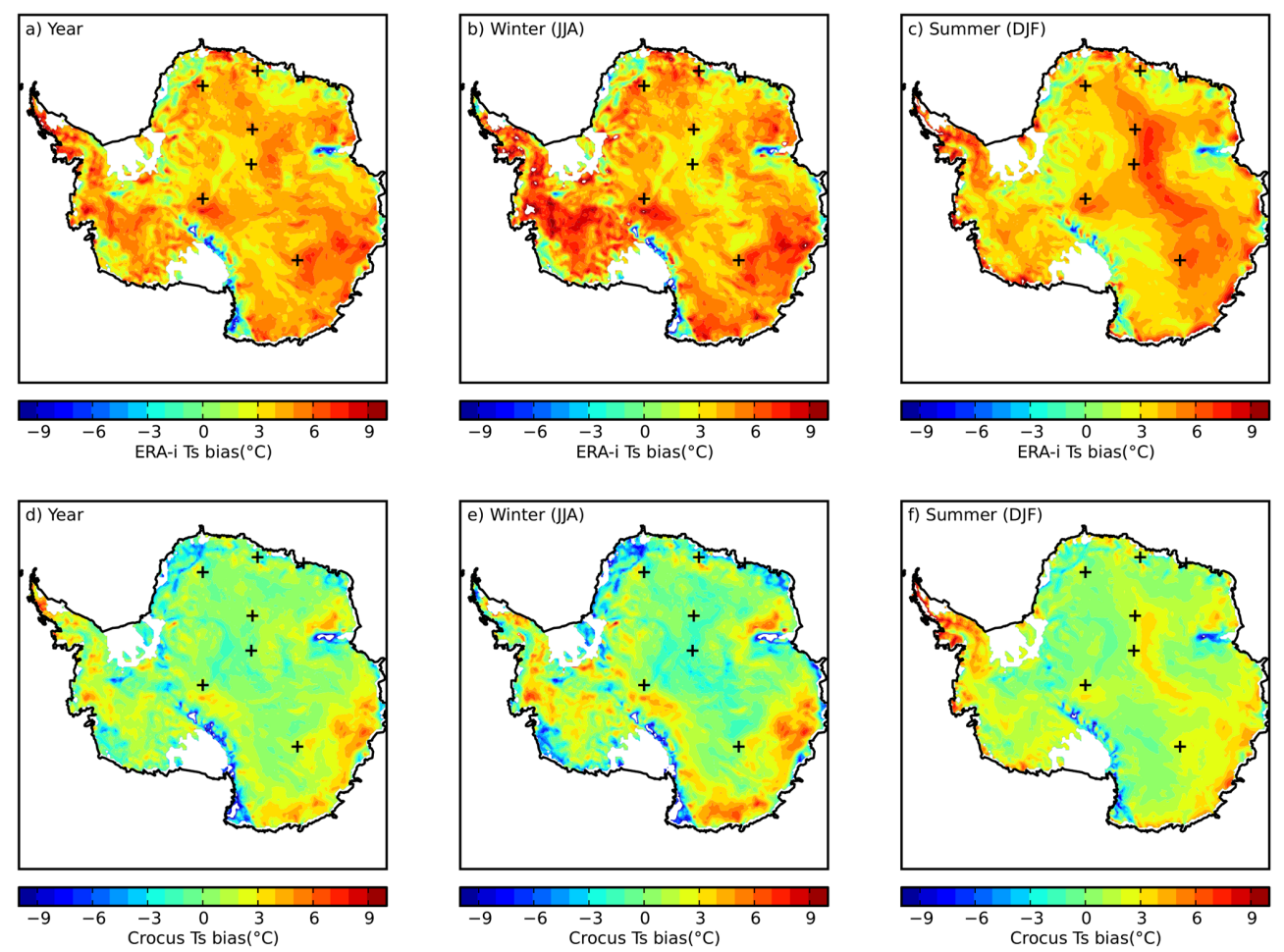

Figure 3. (a) 2000-2011 averaged ERA-i $T_{\mathrm{S}}$ bias, (b) ERA-i $T_{\mathrm{S}}$ bias in winter (JJA) and (c) ERA-i $T_{\mathrm{S}}$ bias in summer (DJF), with respect to MODIS $T_{\mathrm{S}}$. (d) 2000-2011 averaged Crocus $T_{\mathrm{S}}$ bias, (e) Crocus $T_{\mathrm{S}}$ bias in winter (JJA) and (f) Crocus $T_{\mathrm{S}}$ bias in summer (DJF), with respect to MODIS $T_{\mathrm{s}}$.

uses also a version of IFS. Therefore the warm bias detected in our study is consistent with the Genthon et al. (2010) results. However, our comparison with MODIS $T_{\mathrm{S}}$ shows that the warm bias in ERA-Interim $T_{\mathrm{s}}$ affects most of the plateau (and even most of Antarctica) and all seasons, including the long polar night, which means that it cannot be due to an underestimation of the albedo alone. We derived the difference in elevation between the ERA-Interim grid and the topography from Bamber and Gomez-Dans (2005). The difference is very low over most of the plateau (less than $100 \mathrm{~m}$ with no systematic positive or negative bias), which shows that the ERA-Interim widespread warm bias cannot stem from biases in the grid elevation. Figure 5 shows the comparison between ERA-i $T_{\mathrm{S}}$ and in situ observations used in Sect. 3.1 at four stations (Dome C, South Pole, Plateau Station B and Pole of Inaccessibility) during 2009. The left column (Fig. 5a, c, e and g) compares ERA-i $T_{\mathrm{S}}$ with all available in situ observations, corresponding to all-weather conditions, while the right column (Fig. 5b, d, f and h) uses only in situ observations when MODIS $T_{\mathrm{s}}$ is available at the same time, which corresponds to clear-sky conditions. The comparison with in situ surface temperature under clear-sky conditions clearly confirms the warm bias detected over the entire plateau with MODIS $T_{\mathrm{S}}$. The warm bias is slightly lower when all weather conditions are considered but is still quite significant $(+3.2,+3.0,+3.2$ and $+3.0^{\circ} \mathrm{C}$, respectively). This means that ERA-i $T_{\mathrm{s}}$ ex- hibits a warm bias even under cloudy conditions. In the same way Fig. 6 compares Crocus $T_{\mathrm{S}}$ with in situ observations. Crocus $T_{\mathrm{S}}$ exhibits a very low bias $(-0.5,-0.3,-0.3$ and $-0.4^{\circ} \mathrm{C}$ respectively for all-weather conditions and -0.6 , $+0.2,-0.1$ and $-0.2{ }^{\circ} \mathrm{C}$ respectively for clear-sky conditions), confirming the previous comparison with MODIS $T_{\mathrm{s}}$. In Fig. 2d, comparing MODIS $T_{\mathrm{S}}$ to in situ $T_{\mathrm{S}}$ at Plateau Station $\mathrm{B}$, we observe twofold behavior at higher $T_{\mathrm{S}}$ which are not shown in Fig. 5e, f, e and f. It probably reveals cases where false cloud detections induce underestimated MODIS $T_{\mathrm{s}}$. Crocus $T_{\mathrm{S}} \mathrm{RMSE}$ is remarkably low (from 3.1 to $4.4^{\circ} \mathrm{C}$ ) considering the errors in the hourly in situ observations and the uncertainties in the ERA-Interim forcing. Consequently, the evaluation against in situ observations is very consistent with the one made against MODIS $T_{\mathrm{S}}$ on the whole plateau, increasing the confidence in the ERA-i $T_{\mathrm{s}}$ warm bias.

\subsection{Possible impact of the ERA-i $T_{\mathrm{S}}$ warm bias on ERA-i $T_{2 m}$ over the Antarctic Plateau}

The warm bias in ERA-i $T_{\mathrm{s}}$ undoubtedly has an impact on the ERA-Interim $T_{2 \mathrm{~m}}$. Indeed, the latter is not produced by the analysis scheme but by a diagnosis from the surface temperature and the air temperature at the lowest atmospheric vertical level of IFS. Air temperature in the lowest atmospheric levels is constrained very weakly by the observations 

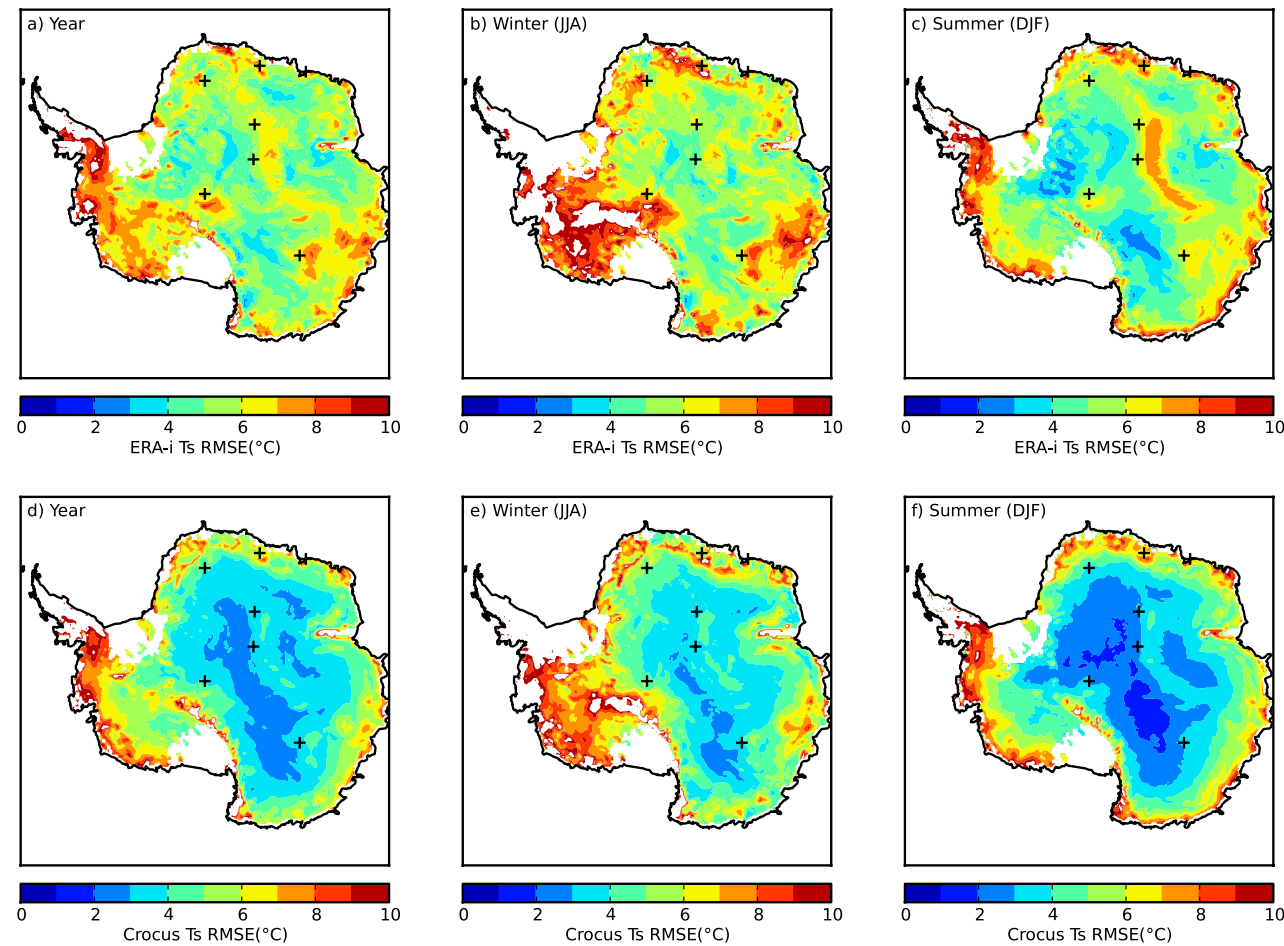

Figure 4. (a) 2000-2011 averaged ERA-i $T_{\mathrm{S}}$ RMSE, (b) ERA-i $T_{\mathrm{S}}$ RMSE in winter (JJA) and (c) ERA-i $T_{\mathrm{S}}$ RMSE in summer (DJF), with respect to MODIS $T_{\mathrm{S}}$. (d) 2000-2011 averaged Crocus $T_{\mathrm{S}} \mathrm{RMSE}$, (e) Crocus $T_{\mathrm{S}} \mathrm{RMSE}$ in winter (JJA) and (f) Crocus $T_{\mathrm{S}}$ RMSE in summer (DJF), with respect to MODIS $T_{\mathrm{s}}$.

in the Antarctic Plateau because of both the scarcity in radiosoundings and the absence of low-level observations by satellite sounders (Rabier et al., 2010). Hence ERA-Interim $T_{2 \mathrm{~m}}$ evolves almost freely under the combined influence of both surface temperature, derived from the surface energy budget, and temperature of higher levels in the atmosphere. In Fig. 7 we compare ERA-Interim $T_{2 \mathrm{~m}}$ with in situ $T_{\text {air }}$ observed at Kohnen (AWS9), Plateau Station B (AWS12), Pole of Inaccessibility (AWS13) and Princess Elisabeth (AWS16). Measuring air temperature over the Antarctic Plateau at stations where no permanent staff can perform maintenance is challenging. There are specific issues, among which the riming of the shelter and the changing elevation of the sensor between visits, due to snowfall accumulation, riming/sublimation and occasional snow drift deposits or erosion. In the left column (Fig. 7a, c, e and f) the air temperature $\left(T_{\text {air }}\right)$ is the temperature as measured on the AWS at a level above the surface between 2 and $4 \mathrm{~m}$, changing with the accumulation. In the right column (Figs. 7b, d and g) the $2 \mathrm{~m}$ air temperature $\left(T_{2 \mathrm{~m}}\right)$ is determined from the AWS observations based on an energy balance model. Stability values determined in this model are used to correct the air temperature values to a fixed height of $2 \mathrm{~m}$ above the surface. Due to problems with the wind speed sensor, we were not able to correct the air temperature at the Pole of Inaccessibility (AWS13). The height above the surface of that sensor is about $4 \mathrm{~m}$, and not changing much.
Note that the energy balance calculations developed at Institute for Marine and Atmospheric Research Utrecht, University of Utrecht, are not published. Figure 7 unambiguously shows that ERA-Interim air temperature at $2 \mathrm{~m}$ exhibits a positive bias from 1.93 to $3.68^{\circ} \mathrm{C}$ at all stations located on the plateau. This bias is consistent with a recent study from Jones and Harpham (2013) showing that the main discrepancy between ERA-Interim and HadCRUT4 $T_{2 \mathrm{~m}}$ over all continental surfaces is a warm bias in East Antarctica. It is also consistent with the positive bias of $T_{\mathrm{S}}$ revealed both from MODIS $T_{\mathrm{s}}$ and in situ $T_{\mathrm{s}}$. For Kohnen, Plateau Station B and Pole of Inaccessibility, the cloud of points exhibits a particular feature: for the coldest observed temperatures, ERA-i $T_{2 \mathrm{~m}}$ stays systematically warmer than in situ observations. The same feature appears also for $T_{\mathrm{S}}$ (Fig. 5). Indeed, these cases correspond to meteorological situations with the more stable boundary layer, showing once more the mentioned weakness in the ERA-Interim parameterization of turbulent fluxes. In contrast to the stations located on the plateau, Princess Elisabeth Station is located on a coastal and mountainous region which strongly limits the validity of comparing ERA-Interim interpolated $T_{2 \mathrm{~m}}$ with a local station.

\subsection{Causes of the ERA-Interim warm bias}

In order to identify the origin of this warm bias, Fig. 8 shows the time series of the difference between observed and 

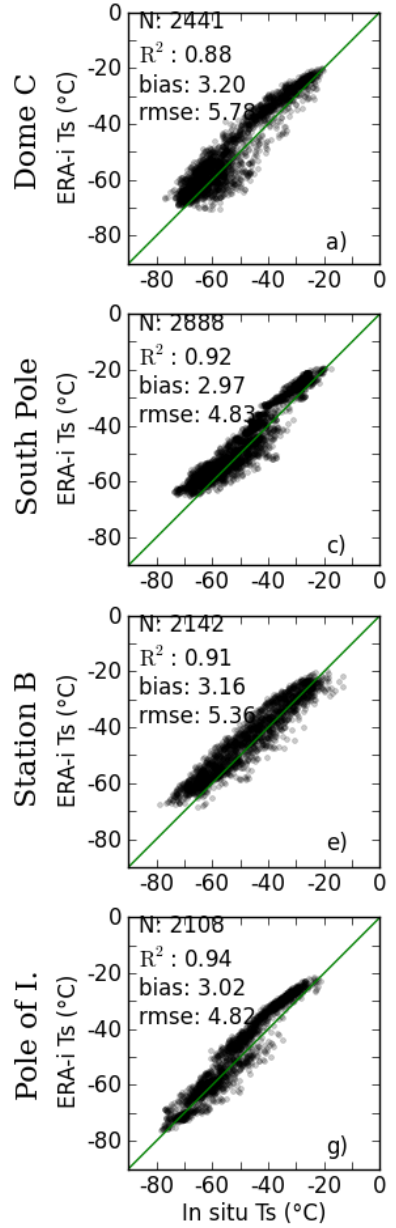

Figure 5. Comparisons of ERA-i $T_{\mathrm{S}}$ and in situ $T_{\mathrm{S}}$ at (a) Dome C, (c) South Pole, (e) Plateau Station B and (g) Pole of Inaccessibility. Same comparisons but only when MODIS $T_{\mathrm{S}}$ values are available at the same time: (b) Dome C, (d) South Pole, (f) Plateau Station $\mathrm{B}$ and (h) Pole of Inaccessibility. The green line represents the $1: 1$ line.

modeled variables from 2 August to 20 September 2009 at the South Pole. This period is illustrative of the general behavior of these variables during the polar night. First, ERAInterim simulates the presence of clouds in a very realistic way. ERA-Interim clouds are detected by the difference between the ERA-Interim $\mathrm{LW}_{\text {down }}$ (red dotted line on the bottom panel) and the ERA-Interim clear-sky $\mathrm{LW}_{\text {down }}$, leading to the blue dotted line on the bottom panel, which represents the contribution of ERA-Interim cloudiness to $\mathrm{LW}_{\text {down }}$. Values equal to 0 indicate cloud-free conditions in ERA-Interim. Actual cloudy conditions can be identified by the peaks in the observed $\mathrm{LW}_{\text {down }}$ above the baseline clear-sky value, which is around $70 \mathrm{~W} \mathrm{~m}^{-2}$ during the considered period. Although ERA-Interim detects most of the actual cloudy conditions, the comparison shows that it underestimates the infrared emissivity of the clouds. Of note is the asymmetry between the periods of increasing and decreasing surface temperature.
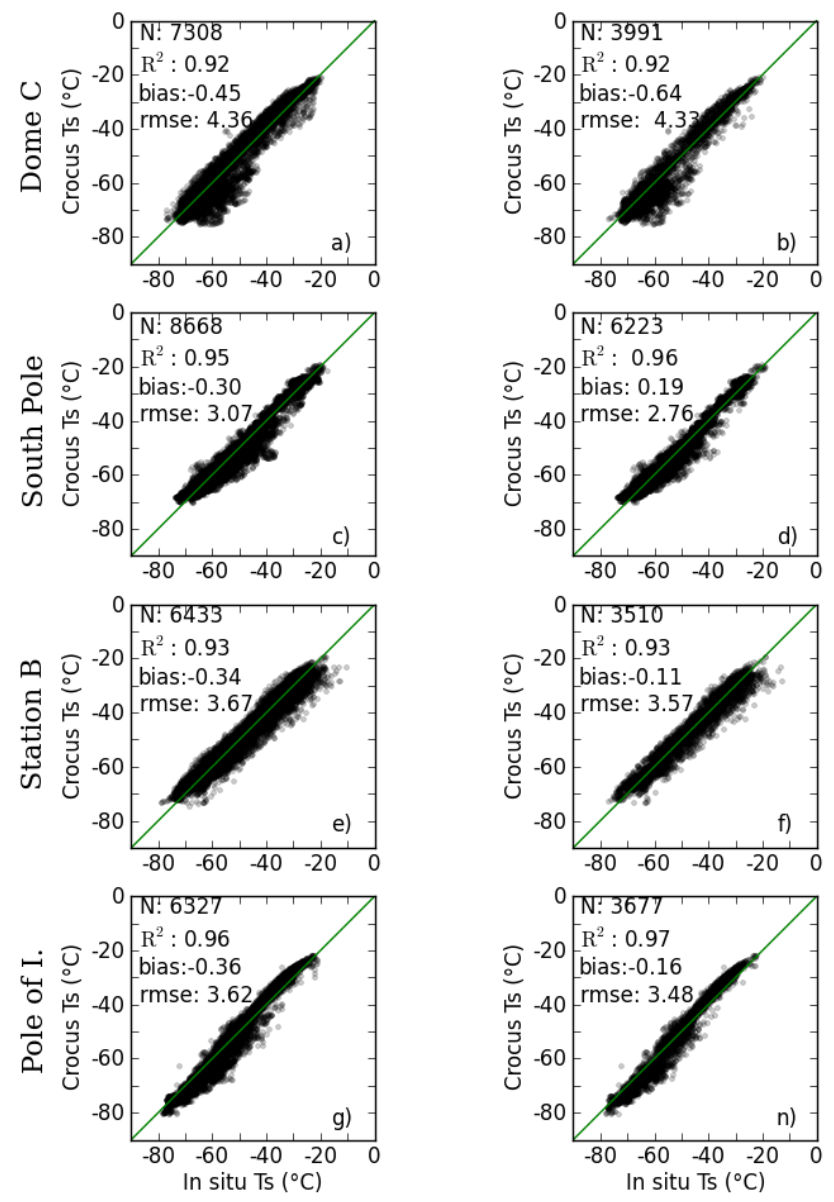

Figure 6. Comparisons of Crocus $T_{\mathrm{S}}$ and in situ $T_{\mathrm{S}}$ at (a) Dome C, (c) South Pole, (e) Plateau Station B and (g) Pole of Inaccessibility. Same comparisons but only when MODIS $T_{\mathrm{S}}$ values are available at the same time: (b) Dome C, (d) South Pole, (f) Plateau Station $\mathrm{B}$ and (h) Pole of Inaccessibility. The green line represents the $1: 1$ line.

During periods of increase, which generally correspond to increasing cloudiness, ERA-i $T_{\mathrm{S}}$ increases at a realistic rate. In the latter case, ERA-i $T_{\mathrm{S}}$ starts to decrease at a realistic rate but this rate slows down rapidly, leading to an overestimation of ERA-i $T_{\mathrm{s}}$, often higher than $+5^{\circ} \mathrm{C}$. Crocus $T_{\mathrm{S}}$ does not show the same behavior, except when the difference between ERA-i $T_{\mathrm{S}}$ and the actual surface temperature is too high, as illustrated around 18 August. This is due to the warm bias in ERA-Interim $T_{2} \mathrm{~m}$ which is used by Crocus and hence impacts Crocus $T_{\mathrm{S}}$ as well. Most meteorological models parameterize the effects of stability in the calculation of the surface exchange coefficients which are used to derive the turbulent fluxes between the surface and the lowest atmospheric level. For the combined reasons described below, we think that the detected overestimation of ERA-i $T_{\mathrm{S}}$ stems from this parameterization in IFS: 

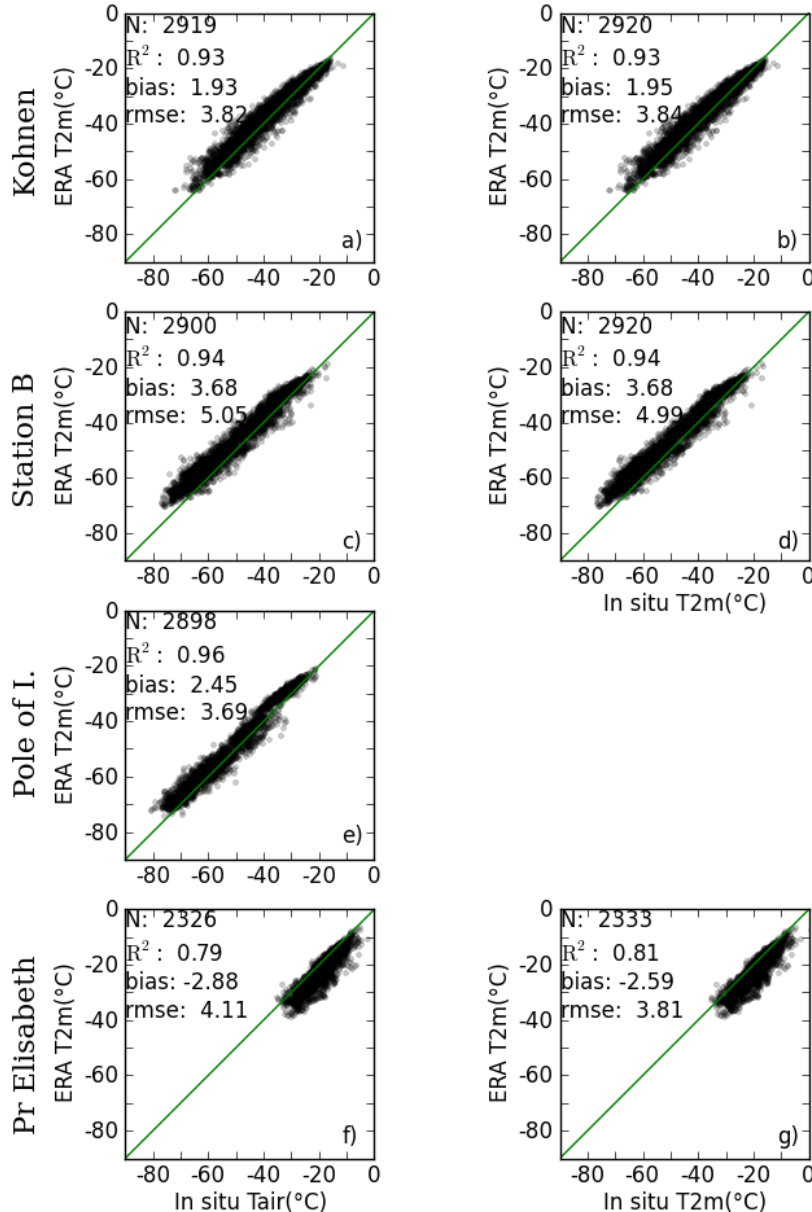

Figure 7. Left column: comparisons of ERA-i $T_{2} \mathrm{~m}$ and in situ $T_{\text {air }}$ at (a) Kohnen (2892 ma.s.l., $\left.z_{\text {ERA-i }}=2867 \mathrm{~m}\right)$, (c) Plateau Station B (3619 ma.s.1, $\left.z_{\text {ERA-i }}=3617 \mathrm{~m}\right)$, (d) Pole of Inaccessibility ( $3718 \mathrm{~m}$ a.s.l., $z_{\text {ERA }-\mathrm{i}}=3746 \mathrm{~m}$ ) and (f) Princess Elisabeth (1372 m a.s.1, $z_{\text {ERA-i }}=1316 \mathrm{~m}$ ) during 2009 . Right column: comparisons of ERA-i $T_{2 \mathrm{~m}}$ and in situ $T_{2 \mathrm{~m}}$ at (b) Kohnen, (d) Plateau Station B and (g) Princess Elisabeth during 2009. The green line represents the $1: 1$ line.

- We evaluate the product ERA-i/land $T_{\mathrm{S}}$ which is produced by a stand-alone simulation of HTESSEL (Balsamo et al., 2009), the new surface scheme developed at ECMWF. Similarly to Crocus $T_{\mathrm{S}}$ simulations, ERAi/land $T_{\mathrm{S}}$ values were simulated from ERA-Interim forcing. They exhibit a warm bias similar to ERA-i $T_{\mathrm{S}}$ bias. HTESSEL uses the same parameterization of the surface exchanges as IFS (stability function from Högström (1988)), in contrast to the formulation used in SURFEX and consequently in Crocus (Louis (1979) modified by Mascart et al. (1995), including a limitation of the maximum Richardson number).

- Though HTESSEL has a better description of snow processes than the land scheme TESSEL (Tiled ECMWF

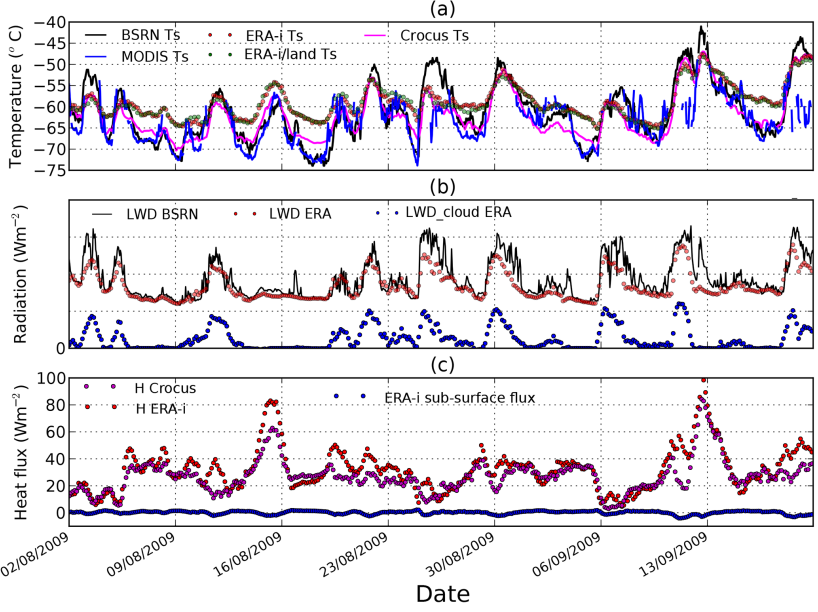

Figure 8. (a) Comparison between different observations of surface temperature at the South Pole: BSRN $T_{\mathrm{S}}$ (solid black curve), Crocus $T_{\mathrm{S}}$ (solid pink curve), ERA-i $T_{\mathrm{S}}$ (red point), LST MODIS (solid blue curve) and ERA-i/land $T_{\mathrm{S}}$ (green point). (b) Comparison between thermal radiations: BSRN LW down (solid black curve), ERA-i LW down $_{\text {(red point) and ERA-i LW }}$ down_cloud $($ blue point). ERA-i $\mathrm{LW}_{\text {down cloud }}$ was obtained by the difference between ERAi LW down $_{\text {and }}$ ERA-i clear-sky $\mathrm{LW}_{\text {down }}$. (c) Comparison between turbulent fluxes of sensible heat: Crocus $H$ (violet point), ERA-i $H$ (red point) and ERA-i sub-surface flux (blue point).

Scheme for Surface Exchanges over Land) used in IFS, ERA-i/land $T_{\mathrm{S}}$ does not significantly differ from ERAi $T_{\mathrm{s}}$. There are several differences between Crocus and HTESSEL, especially in terms of albedo and snow density, but they cannot explain the differences between their respective simulations shown in Fig. 8: there is almost no solar radiation at this time of the year, and differences in the snow heat capacity and conductivity cannot lead to a long-lasting constant difference in surface temperature, as observed from 13 to 19 August. Sub-surface flux in ERA-Interim has been derived from the temperature difference between the surface and the thermally active snow layer. Figure $8 \mathrm{c}$ shows that it is always very low (absolute value less than $5 \mathrm{~W} \mathrm{~m}^{-2}$ ). This is due to the large depth of this layer $(1 \mathrm{~m}$ at the South Pole), which leads to an overestimation of the thermal resistance and an underestimation of the conductive heat fluxes between the sub-surface and the surface. While this TESSEL feature cannot explain the overestimation of ERA-i $T_{\mathrm{s}}$, it must be noticed that it should introduce significant error on the sub-daily timescales.

- Figure 8c shows that the sensible heat fluxes are much larger in ERA-Interim than in Crocus simulations when ERA-i $T_{\mathrm{S}}$ and Crocus $T_{\mathrm{S}}$ are close. Latent heat fluxes are not shown in Fig. 8c because they are almost negligible during the period (absolute value less than $2 \mathrm{~W} \mathrm{~m}^{-2}$ in both ERA-Interim and Crocus simulation) and cannot 
explain the overestimation of ERA-i $T_{\mathrm{s}}$. In general, the surface sensible heat fluxes from the atmosphere towards the surface are very high in ERA-Interim, as shown in Fig. 9 for August 2009. On most of the plateau, the mean fluxes are higher than $20 \mathrm{~W} \mathrm{~m}^{-2}$ and even higher than $30 \mathrm{~W} \mathrm{~m}^{-2}$ over large areas. Such permanent high fluxes at high-elevation and low-wind sites are incompatible with those reported in the literature. Reijmer and Oerlemans (2002) derived a mean sensible heat flux at Kohnen (AWS 9) around $12 \mathrm{~W} \mathrm{~m}^{-2}$ in August, which is in agreement with the sensible heat fluxes calculated in winter at Kohnen by Van den Broeke et al. (2005a, b), while mean ERA-Interim fluxes reach $25 \mathrm{~W} \mathrm{~m}^{-2}$ at the corresponding points during August 2009.

- ERA-i $T_{\mathrm{S}}$ overestimation cannot be due to an overestimation of $\mathrm{LW}_{\text {down }}$ because it would impact Crocus $T_{\mathrm{s}}$ similarly, which is not the case. Furthermore, Fig. 8 shows that during August 2009, the largest bias occurred at the South Pole under clear-sky conditions at periods when $\mathrm{LW}_{\text {down }}$ was perfectly represented in ERA-Interim.

- Figure 5 clearly shows a systematic overestimation of ERA-i $T_{\mathrm{S}}$ during the coldest periods at each individual station. It seems that ERA-i $T_{\mathrm{S}}$ cannot drop low enough during these situations, as already discussed from the time series in Fig. 8. These periods correspond to an extremely low $\mathrm{LW}_{\text {down }}$ which induces a strong radiative cooling at the surface and thus leads to very stable conditions. The shape of the cloud of points is very similar to the shape of the cloud of points in the left column of figure 3 in Jones and Harpham (2013) which compares ERA-Interim and HadCRUT4 $T_{2 \mathrm{~m}}$ in Antarctica. This is also the case for the lowest $T_{2 \mathrm{~m}}$ during DJF north of $60^{\circ} \mathrm{N}$ (Jones and Harpham, 2013, left column, raw 4), revealing that the ERA-Interim warm bias is not specific to Antarctica. It also affects northern Eurasia in winter, an additional element calling into question the representation of the surface turbulent exchanges under very stable conditions, especially when the ground is covered by snow.

The difficulty of properly estimating the surface turbulent fluxes under very stable conditions has been extensively documented (for example Brun et al. (1997), Martin and Lejeune (1998), Essery and Etchevers (2004), Anderson and Neff (2008), Sukoriansky et al. (2006), Town and Walden (2009), Genthon et al. (2010), Holtslag et al. (2013)). Ad hoc treatments are often introduced in meteorological and snow models to solve the problem, as was done in SURFEX/Crocus with the introduction of the limitation in the Richardson number. This is treated differently in IFS, which could explain the warm bias. Holtslag et al. (2013) show that $T_{2 \mathrm{~m}}$ forecasted in winter over snow-covered areas with IFS is much more sensitive to slight changes in the stability functions with the current version of IFS than they were in previous versions. In order to demonstrate the sensitivity of $T_{\mathrm{S}}$ to air temperature and to the representation of surface turbulent fluxes, four numerical experiments were made with Crocus under the following configurations: three experiments with a constant change in ERA-Interim $T_{2 \mathrm{~m}}$ of $+2,-2$ and $-4{ }^{\circ} \mathrm{C}$, respectively, and an additional experiment with a change in ERA-Interim $T_{2 \mathrm{~m}}$ of $-4{ }^{\circ} \mathrm{C}$ and a change in the maximum Richardson number from its original 0.2 value to 0.1 , which enhances the turbulent fluxes towards the surface in very stable conditions. The comparison with the control experiment in July 2009 leads to the following conclusions:

- The impact of the sole changes in the forcing air temperature leads to a change in Crocus $T_{\mathrm{S}}$ equal to only about half of the air temperature change. It shows how very stable conditions attenuate the impact of $T_{2 \mathrm{~m}}$ on the surface temperature.

- A lower maximum Richardson number used in Crocus almost balances the air temperature decrease of $-4{ }^{\circ} \mathrm{C}$ over a large part of the Antarctic Plateau.

The last experiment clearly shows how a small change in the parameterization of the effects of stability on the surface exchange coefficients drastically changes the snow surface temperature.

\section{Conclusions}

Thanks to its orbital characteristics and to its large swath width, MODIS shows great potential in the observation of the surface temperature of the Antarctic Plateau under clearsky conditions. Thus, more than 9 hourly observations per day are retrieved on average on the plateau, and they compare very well with in situ surface temperature observations, in terms of both bias and RMSE. To our knowledge, no previous study has performed an evaluation of MODIS LST with as much detail and as many in situ observations. Further, by comparing in situ surface temperature instead of in situ nearsurface air temperature, we avoid the uncertainties in the observation of $T_{2 \mathrm{~m}}$ over the Antarctic Plateau as documented in Genthon et al. (2010).

Hourly MODIS $T_{\mathrm{s}}$ from 2000 to 2011 was used to evaluate the accuracy of snow surface temperature in the ERA-Interim reanalysis and the one produced by a stand-alone simulation with the Crocus snowpack model using ERA-Interim forcing. It reveals that ERA-Interim has a widespread warm bias on the Antarctic Plateau, ranging from +3 to $+6^{\circ} \mathrm{C}$ depending on the location. This is consistent with a recent comparison of ERA-Interim $T_{2 \mathrm{~m}}$ with the HadCRUT4 data set (Jones and Harpham, 2013). Considering the very low constraint by the observations of the analyzed ABL temperature in ERAInterim, the warm bias $2 \mathrm{~m}$ above the surface is due mainly to 

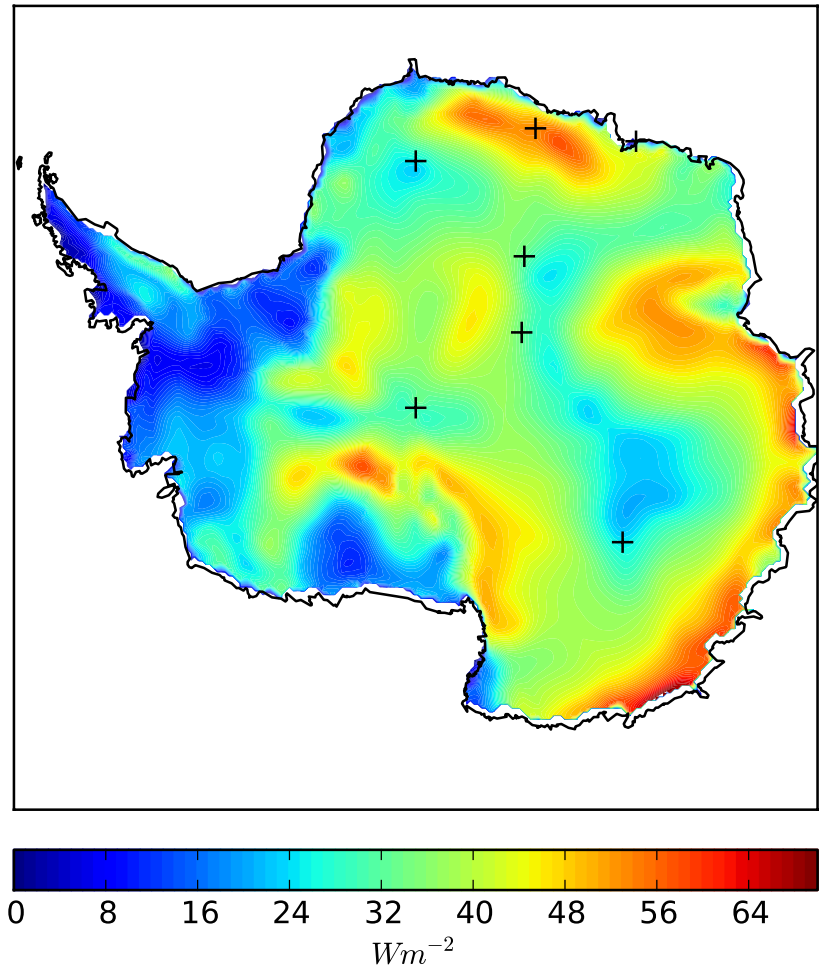

Figure 9. Averaged ERA-i sensible heat fluxes from the atmosphere towards the surface in August 2009.

the bias at the snow surface. Comparison with in situ surface temperature shows that this bias is not limited to clear-sky conditions. At this stage, it is difficult to estimate the impact of this bias on other ERA-Interim variables, such as temperature and humidity in the ABL and snow accumulation. A detailed comparison with Crocus outputs and with the ERAInterim/land stand-alone outputs by the new ECMWF land scheme (Balsamo et al., 2012) shows that the warm bias may be due primarily to the overestimation of the surface turbulent sensible heat fluxes in very stable conditions. Numerical experiments with Crocus show that small changes in the turbulent flux parameterization strongly impact surface temperature, highlighting the sensitivity of simulated surface temperatures to poorly known parameters.

According to the method developed in this study, hourly MODIS $T_{\mathrm{S}}$ in Antarctica is particularly well suited for evaluating the surface temperature simulated by various types of models: meteorological models, global or regional climate models and stand-alone snow models. This should help in the identification of current model weaknesses and lead to improved future reanalyses, which are necessary for a better detection and understanding of climate change in Antarctica.
Acknowledgements. This study is a contribution to the international Concordiasi project currently supported by the following agencies: Météo-France; CNES; CNRS/INSU; NSF; NCAR; University of Wyoming; Purdue University; University of Colorado; the Alfred Wegener Institute; the Met Office; and ECMWF. It was funded by the European Commission's 7th Framework Programme, under grant agreement no. 226520, COMBINE project. Part of the data at Dome $\mathrm{C}$ were acquired by the CALVA/NIVO IPEV programs. Installation and operation of AWS12 and 13 have been made possible with support from the Netherlands Polar Programme and the Norwegian-US Scientific Traverse of East Antarctica. The installation and maintenance of AWS16 was financed by the Belgian Science Policy Office under grant number EN/01/4B supervised by Nicole van Lipzig and Irina Gorodetskaya (KU Leuven). We thank D. Longenecker of NOAA for providing the South Pole BSRN data, and G. Balsamo from ECMWF and O. Traullé from CNRM/GAME for fruitful discussions. We acknowledge funding from the CNES/TOSCA program.

Edited by: E. Larour

\section{References}

Anderson, P. S. and Neff, W. D.: Boundary layer physics over snow and ice, Atmos. Chem. Phys., 8, 3563-3582, doi:10.5194/acp-83563-2008, 2008.

Balsamo, G., Beljaars, A., Scipal, K., Viterbo, P., van den Hurk, B., Hirschi, M., and Betts, A. K.: A revised hydrology for the ECMWF model: Verification from field site to terrestrial water storage and impact in the Integrated Forecast System, J. Hydrometeorol., 10, 623-643, 2009.

Balsamo, G., Albergel, C., Beljaars, A., Boussetta, S., Brun, E., Cloke, H., Dee, D., Dutra, E., Pappenberger, F., de Rosnay, P., Muñoz-Sabater, J., Stockdale, T., and Vitart, F.: ERAInterim/Land: A global land-surface reanalysis based on ERAInterim meteorological forcing, ERA Report Series, ECMWF, Shinfield Park, Reading, 2012.

Bamber, J. and Gomez-Dans, J. L.: The accuracy of digital elevation models of the Antarctic continent, Earth Planet. Sc. Lett., 237, 516-523, 2005.

Bromwich, D. H., Nicolas, J. P., Hines, K. M., Kay, J. E., Key, E. L., Lazzara, M. A., Lubin, D., McFarquhar, G. M., Gorodetskaya, I. V., Grosvenor, D. P., Lachlan-Cope, T., and van Lipzig, N. P. M.: Tropospheric clouds in Antarctica, Rev. Geophys., 50, RG1004, doi:10.1029/2011RG000363, 2012.

Bromwich, D. H., Otieno, F. O., Hines, K. M., Manning, K. W., and Shilo, E.: Comprehensive evaluation of polar weather research and forecasting model performance in the Antarctic, J. Geophys. Res.-Atmos., 118, 274-292, 2013.

Brun, E., David, P., Sudul, M., and Brunot, G.: A numerical model to simulate snow-cover stratigraphy for operational avalanche forecasting, J. Glaciol., 38, 13-22, 1992.

Brun, E., Martin, E., and Spiridonov, V.: The coupling of a multilayered snow model with a GCM, Ann. Glaciol., 25, 66-72, 1997.

Brun, E., Six, D., Picard, G., Vionnet, V., Arnaud, L., Bazile, E., Boone, A., Bouchard, A., Genthon, C., Guidard, V., Le Moigne, P., Rabier, F., and Seity, Y.: Snow/atmosphere coupled simulation at Dome C, Antarctica, J. Glaciol., 52, 721-736, 2011. 
Comiso, J.: Variability and trends in Antarctic surface temperatures from in situ and satellite infrared measurements, J. Climate, 13, 1674-1696, 2000.

Dee, D., Uppala, S., Simmons, A., Berrisford, P., Poli, P., Kobayashi, S., Andrae, U., Balmaseda, M., Balsamo, G., Bauer, P., Bechtold, P., Beljaars, A. C. M., van de Berg, L., Bidlot, J., Bormann, N., Delsol, C., Dragani, R., Fuentes, M., Geer, A. J., Haimberger, L., Healy, S. B., Hersbach, H., Hólm, E. V., Isaksen, L., Kållberg, P., Köhler, M., Matricardi, M., McNally, A. P., Monge-Sanz, B. M., Morcrette, J. J., Park, B. K., Peubey, C., de Rosnay, P., Tavolato, C., Thépaut, J. N., and Vitart, F.: The ERA-Interim reanalysis: Configuration and performance of the data assimilation system, Q. J. Roy. Meteor. Soc., 137, 553-597, 2011.

Dozier, J. and Warren, S.: Effect of viewing angle on the infrared brightness temperature of snow, Water Resour. Res., 18, 14241434, 1982.

Essery, R. and Etchevers, P.: Parameter sensitivity in simulations of snowmelt, J. Geophys. Res.-Atmos., 109, D20111, doi:10.1029/2004JD005036, 2004.

Gallée, H. and Gorodetskaya, I. V.: Validation of a limited area model over Dome C, Antarctic Plateau, during winter, Clim. Dynam., 34, 61-72, 2010.

Genthon, C., Town, M., Six, D., Favier, V., Argentini, S., and Pellegrini, A.: Meteorological atmospheric boundary layer measurements and ECMWF analyses during summer at Dome C, Antarctica, J. Geophys. Res., 115, D20111, doi:10.1029/2009JD012741, 2010.

Gorodetskaya, I. V., Van Lipzig, N., Broeke, M., Mangold, A., Boot, W., and Reijmer, C.: Meteorological regimes and accumulation patterns at Utsteinen, Dronning Maud Land, East Antarctica: Analysis of two contrasting years, J. Geophys. Res.-Atmos., 118, 1700-1715, 2013.

Hall, D. K., Box, J. E., Casey, K. A., Hook, S. J., Shuman, C. A., and Steffen, K.: Comparison of satellite-derived and in-situ observations of ice and snow surface temperatures over Greenland, Remote Sens. Environ., 112, 3739-3749, 2008.

Hall, D. K., Comiso, J. C., DiGirolamo, N. E., Schuman, C. A., Key, J. R., and Koenig, L. S.: A satellite-derived climate-quality data record of the clear-sky surface temperature of the Greenland ice sheet, J. Climate, 25, 4785-4798, 2012.

Hall, D. K., Comiso, J. C., DiGirolamo, N. E., Shuman, C. A., Box, J. E., and Koenig, L. S.: Variability in the surface temperature and melt extent of the Greenland ice sheet from MODIS, Geophys. Res. Lett., 40, 2114-2120, 2013.

Högström, U.: Non-dimensional wind and temperature profiles in the atmospheric surface layer: A re-evaluation, Bound.-Layer Meteor., 42, 55-78, 1988.

Holtslag, A., Svensson, G., Baas, P., Basu, S., Beare, B., Beljaars, A., Bosveld, F., Cuxart, J., Lindvall, J., Steeneveld, G., Tjernström, M., and van de Wiel, B. J. H.: Stable Atmospheric Boundary Layers and Diurnal Cycles-Challenges for Weather and Climate Models, B. Am. Meteorol. Soc., 94, 1691-1706, 2013.

Jones, P. and Harpham, C.: Estimation of the absolute surface air temperature of the Earth, J. Geophys. Res.-Atmos., 118, 32133217, 2013.

Louis, J.: A parametric model of vertical eddy fluxes in the atmosphere, Bound.-Lay. Meteorol., 17, 187-202, 1979.
Martin, E. and Lejeune, Y.: Turbulent fluxes above the snow surface, Ann. Glaciol., 26, 179-183, 1998.

Mascart, P., Noilhan, J., and Giordani, H.: A modified parameterization of flux-profile relationships in the surface layer using different roughness length values for heat and momentum, Bound.Lay. Meteorol., 72, 331-344, 1995.

Masson, V., Le Moigne, P., Martin, E., Faroux, S., Alias, A., Alkama, R., Belamari, S., Barbu, A., Boone, A., Bouyssel, F., Brousseau, P., Brun, E., Calvet, J.-C., Carrer, D., Decharme, B., Delire, C., Donier, S., Essaouini, K., Gibelin, A.-L., Giordani, H., Habets, F., Jidane, M., Kerdraon, G., Kourzeneva, E., Lafaysse, M., Lafont, S., Lebeaupin Brossier, C., Lemonsu, A., Mahfouf, J.-F., Marguinaud, P., Mokhtari, M., Morin, S., Pigeon, G., Salgado, R., Seity, Y., Taillefer, F., Tanguy, G., Tulet, P., Vincendon, B., Vionnet, V., and Voldoire, A.: The SURFEXv7.2 land and ocean surface platform for coupled or offline simulation of earth surface variables and fluxes, Geosci. Model Dev., 6, 929-960, doi:10.5194/gmd-6-929-2013, 2013.

Ohmura, A., Gilgen, H., Hegner, H., Müller, G., Wild, M., Dutton, E. G., Forgan, B., Fröhlich, C., Philipona, R., Heimo, A., König-Langlo, G., McArthur, B., Pinker, R., Whitlock, C. H., and Dehne, K.: Baseline Surface Radiation Network (BSRN/WCRP): New precision radiometry for climate research, B. Am. Meteorol. Soc., 79, 2115-2136, 1998.

Rabier, F., Bouchard, A., Brun, E., Doerenbecher, A., Guedj, S., Guidard, V., Karbou, F., Peuch, V.-H., El Amraoui, L., Puech, D., Genthon, C., Picard, G andTown, M., Hertzog, A., Vial, F., Cocquerez, P., Cohn, S. A., Hock, T., Fox, J., Cole, H., Parsons, D., Powers, J., Romberg, K., VanAndel, J., Deshler, T., Mercer, J., Haase, J. S., Avallone, L., Kalnajs, L., Mechoso, C. R., Tangborn, A., Pellegrini, A., frenot, Y., Thépaut, J. N., McNally, A., Balsamo, G., and Steinle, P.: The Concordiasi project in Antarctica, B. Am. Meteor. Soc., 91, 69-86, 2010.

Reijmer, C. and Oerlemans, J.: Temporal and spatial variability of the surface energy balance in Dronning Maud Land, East Antarctica, J. Geophys. Res., 107, ACL 9-1-ACL 9-12, 2002.

Rignot, E., Velicogna, I., Van den Broeke, M., Monaghan, A., and Lenaerts, J.: Acceleration of the contribution of the Greenland and Antarctic ice sheets to sea level rise, Geophys. Res. Lett., 38, L05503, doi:10.1029/2011GL046583, 2011.

Schneider, D. P., Steig, E. J., and Comiso, J. C.: Recent climate variability in Antarctica from satellite-derived temperature data, J. Climate, 17, 1569-1583, 2004.

Steig, E. J., Schneider, D. P., Rutherford, S. D., Mann, M. E., Comiso, J. C., and Shindell, D. T.: Warming of the Antarctic ice-sheet surface since the 1957 International Geophysical Year, Nature, 457, 459-462, 2009.

Sukoriansky, S., Galperin, B., and Perov, V.: A quasi-normal scale elimination model of turbulence and its application to stably stratified flows, Nonlinear Proc. Geophy., 13, 9-22, 2006.

Town, M. and Walden, V.: Surface energy budget over the South Pole and turbulent heat fluxes as a function of an empirical bulk Richardson number, J. Geophys. Res., 114, D22107, doi:10.1029/2009JD011888, 2009.

van de Berg, W. J., van den Broeke, M. R., and van Meijgaard, E.: Spatial structures in the heat budget of the Antarctic atmospheric boundary layer, The Cryosphere, 2, 1-12, doi:10.5194/tc-2-12008, 2008. 
van den Broeke, M., van As, D., Reijmer, C., and van de Wal, R.: Assessing and improving the quality of unattended radiation observations in Antarctica, J. Atmos. Ocean. Techn., 21, 14171431, 2004.

Van den Broeke, M., Reijmer, C., Van As, D., Van de Wal, R., and Oerlemans, J.: Seasonal cycles of Antarctic surface energy balance from automatic weather stations, Ann. Glaciol., 41, 131139, 2005a.

Van den Broeke, M., Van As, D., Reijmer, C., and Van de Wal, R.: Sensible heat exchange at the Antarctic snow surface: a study with automatic weather stations, Int. J. Climatol., 25, 1081-1101, $2005 b$
Vionnet, V., Brun, E., Morin, S., Boone, A., Faroux, S., Le Moigne, P., Martin, E., and Willemet, J.-M.: The detailed snowpack scheme Crocus and its implementation in SURFEX v7.2, Geosci. Model Dev., 5, 773-791, doi:10.5194/gmd-5-773-2012, 2012.

Wan, Z.: New refinements and validation of the collection-6 MODIS land-surface temperature/emissivity product, Remote Sens. Environ., 140, 36-45, 2014.

Wan, Z. and Dozier, J.: A generalized split-window algorithm for retrieving land-surface temperature from space, IEEE Trans. Geosci. Remote, 34, 892-905, 1996.

Wang, Y., Wang, M., and Zhao, J.: A comparison of MODIS LST retrievals with in situ observations from AWS over the Lambert Glacier Basin, East Antarctica, Int. J. Geosci., 4, 611-617, 2013. 